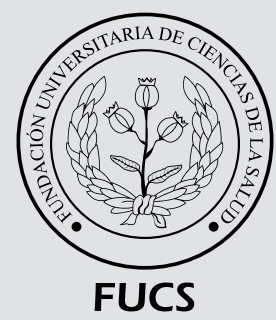

\title{
Resultados comparativos de la prueba Saber 11 antes y durante la pandemia por COVID-19 en una institución educativa de Soacha, Cundinamarca, Colombia
}

Comparative results of the Saber 11 test before and during the COVID-19 pandemic in an educational institution in Soacha, Cundinamarca, Colombia

angeniero. Magister en Gestión de la Tecnología Educativa, Especialista en Administración de la Informática Educativa. Docente de matemáticas e Investigador, Secretaría de Educación de Soacha, Cundinamarca.

\section{R E S U M EN}

Introducción: la afección por coronavirus 2019 (COVID-19) es una enfermedad respiratoria aguda infecciosa CAUSADA por un nuevo coronavirus. La Organización Mundial de la Salud (OMS) fue conocedora de casos de neumonía de etiología microbiana irreconocible, asociados con la ciudad de Wuhan, provincia de Hubei, China, el 31 de diciembre 2019. Objetivo: comparar los resultados de las pruebas Saber 11- 2019 y 11- 2020 durante la pandemia del COVID-19 en la institución educativa General Santander del municipio de Soacha, Cundinamarca, Colombia. Metodología: trabajo de tipo experimental, la información se obtuvo de los resultados de las pruebas Saber 11, 2019 y 2020. Resultados: los promedios en las diferentes asignaturas evaluadas en la prueba no tuvieron diferencias significativas, es decir que no se evidenció una disminución en el resultado global de la prueba en dicha institución. Conclusión: el hecho de que no haya diferencias significativas entre los años 2019 y 2020 radica también en que los estudiantes pertenecen al mismo contexto social y económico.

Historia del artículo:

Fecha recibido: agosto 3 de 2021 Fecha aceptado: septiembre 1 de 2021
Autor para correspondencia: Ing. Jorge Enrique Díaz Pinzón jediazp@unal.edu.co
DOI

10.31260/RepertMedCir.01217372.1259 
Introduction: coronavirus disease 2019 (COVID-19) is an acute respiratory infectious disease caused by a novel coronavirus. The World Health Organization (WHO) was informed of cases of pneumonia of unrecognized microbial etiology detected in Wuhan City, Hubei province in China, on December 31 2019. Objective: to compare the results of the Saber 11- 2019 and 11- 2020 tests, during the COVID-19 pandemic, in the General Santander educational institution located in the municipality of Soacha, Cundinamarca, Colombia. Methodology: an experimental research design was used. Results were obtained from the Saber 11, 2019 and 2020 tests. Results: the averages obtained for the different subjects evaluated in the test did not show significant differences, which indicates there was no evidence of a decrease in the test overall scores in said institution. Conclusion: the fact that there are no significant differences between years 2019 and 2020 also lies in the fact that students belong to the same social and economic context.

Key words: education; comparative evaluation; SABER test; COVID-19.

(C) 2021 Fundación Universitaria de Ciencias de la Salud - FUCS This is an open access article under the CC BY-NC-ND license (http://creativecommons.org/licenses/by-nc-nd/4.0/).

\section{INTRODUCCIÓN}

De acuerdo con la Organización Mundial de la Salud (2020) citado por Díaz, ${ }^{1}$ en diciembre de 2019 apareció una asociación de casos de neumonía en Wuhan (provincia de Hubei, China) con una muestra común en un mercado mayorista de mariscos, pescado y animales vivos. El 7 de enero 2020 las autoridades chinas instauraron como agente promotor del brote a un nuevo virus de la familia corona viridae, que fue designado SARS-COV-2. La secuencia genética fue intervenida por las autoridades chinas el 12 de enero. La enfermedad ocasionada por este nuevo virus se ha designado por consenso internacional COVID-19.

De acuerdo con el Ministerio de Educación Nacional $(\mathrm{MEN})^{2}$, con la prueba Saber 11 se busca el nivel de la educación media con base en el cumplimiento de determinadas competencias que este ente plantea como el objetivo de la educación. Por esta razón a partir de 2014 se ordena a las instituciones de educación básica suministrar información a la comunidad educativa sobre el progreso de las competencias básicas que debe desarrollar un estudiante durante su vida escolar, con el fin de construir un instrumento que retroalimente al sistema educativo. Respecto al examen de estado de la educación media Saber 11, este lo deben presentar los estudiantes que se encuentren finalizando el grado undécimo, con el fin de obtener datos oficiales para efectos de admisión a la educación superior. También pueden tomarlo quienes ya hayan obtenido el título de bachiller o superado el examen de validación del bachillerato según las disposiciones vigentes. $^{3}$

El objetivo de este estudio de investigación es comparar los resultados de la prueba Saber 11- 2019, y 11-2020 durante la pandemia del COVID-19 en la institución educativa General Santander del municipio de Soacha, Cundinamarca, Colombia.

\section{METODOLOGÍA}

El trabajo de investigación se realizó mediante un tipo experimental que es el siguiente: "aquella que permite mayor seguridad al establecer relaciones de causa a efecto pues presenta una visión general y aproximada del objeto de estudio, además de contar con una investigación cuyo diseño establece un método experimental habitual del conjunto de las normas científicas", Monje (2011) citado por Díaz., ${ }^{4,5}$ Según Shuttleworth citado por Díaz ${ }^{6}$, menciona que "regularmente a estos experimentos se los nombra ciencia verdadera y manejan medios matemáticos y estadísticos cotidianos para evaluar los resultados de modo concluyente. Todos los experimentos cuantitativos utilizan un formato estándar con algunas pequeñas diferencias interdisciplinarias para generar una hipótesis que será probada o desmentida. Esta hipótesis debe ser demostrable por medios matemáticos $\mathrm{y}$ estadísticos $\mathrm{y}$ constituye la base alrededor de la cual se diseña todo el experimento".

\section{POBLACIÓN}

La información se obtuvo de los resultados de las pruebas Saber11- 2019 y 2020, de los estudiantes de las jornadas de mañana y tarde en la institución educativa General Santander, del municipio de Soacha, Cundinamarca, Colombia.

\section{FORMULACIÓN DE HIPÓTESIS}

La hipótesis del presente trabajo de investigación se diseña como una relación causal y se enuncia de la siguiente forma: a) hipótesis alterna (Ha): existen diferencias en el 
promedio de los puntajes obtenidos en lectura crítica, matemáticas, ciencias sociales, ciencias naturales, inglés y puntaje total de las Pruebas Saber 11-2019 y 11-2020. b) hipótesis nula (Ho): no hay diferencias en el promedio de los puntajes obtenidos en lectura crítica, matemáticas, ciencias sociales, ciencias naturales, inglés y puntaje total de las pruebas Saber 11-2019 y 11-2020. Nivel de significancia: $=5 \%=0,5$.

Elección de la prueba estadistica: $t$-student, admite decidir si dos variables aleatorias normales (gaussianas) y con igual varianza tienen medias diferentes. Puede emplearse en numerosos contextos para evidenciar si la modificación en las condiciones de un proceso (humano o natural) fundamentalmente aleatorio produce una elevación o disminución de la media poblacional. ${ }^{7}$

Toma de decisión: sí el $p$ - valor < a es aceptar $\mathrm{Ha}$, entonces rechazamos la hipótesis nula y nos quedamos con la hipótesis del investigador (Ha).

Condiciones de aplicación de la prueba t para dos medias: el valor de significancia de la prueba es $=0.05(5 \%)$, cuando es mayor se acepta la hipótesis nula y si es menor se le rechaza. Para una variable aleatoria (numérica) se aplicará la prueba t- de student, para diferencia de medias en muestras independientes. Es una prueba estadística para evaluar si dos grupos difieren entre sí de manera significativa respecto de sus medias, se utilizó el software SPSS v $25.0 .^{8}$

\section{RESULTADOS}

En la tabla 1 se observa la media para cada una de las pruebas, 267 estudiantes presentaron las pruebas Saber 11 en 2019 y 285 en 2020, las que mejoraron el promedio respecto a 2019 fueron: matemáticas 52,55; sociales 51,18; y el puntaje global 256,72. Las pruebas que presentaron disminución en sus resultados fueron: lectura crítica con 53,67; ciencias naturales 49,43 e inglés 47,00.

Tabla 1. Media de las pruebas Saber 11, 2019-2020

\begin{tabular}{|c|c|c|c|}
\hline Prueba & Año & N & Media \\
\cline { 1 - 2 } Lectura crítica & 2019 & 267 & 53,75 \\
& 2020 & 285 & 53,67 \\
\cline { 1 - 1 } Matemáticas & 2019 & 267 & 51,94 \\
& 2020 & 285 & 52,55 \\
\cline { 1 - 1 } Sociales & 2019 & 267 & 47,69 \\
& 2020 & 285 & 51,18 \\
\cline { 1 - 1 } Ciencias naturales & 2019 & 267 & 50,05 \\
& 2020 & 285 & 49,43 \\
\cline { 1 - 1 } Inglés & 2019 & 267 & 50,61 \\
& 2020 & 285 & 47,00 \\
\cline { 1 - 1 } Puntaje global & 2019 & 267 & 254,04 \\
& 2020 & 285 & 256,72 \\
\hline
\end{tabular}

Fuente: el autor
En la tabla 2 se observó a partir del análisis estadístico de los datos aplicando la t-student que el p-valor de la prueba es igual a 0,912 para lectura crítica, 0,062 para matemáticas, 0,463 para para ciencias naturales 0,406, en estos casos son valores mayores a $\alpha=0.05$, que llevan a rechazar la Ha dado que no hay diferencias esenciales entre los promedios para las pruebas SABER-11, $2019 \mathrm{y}$ 2020. El p-valor para las asignaturas de sociales e inglés es de 0,000 , este valor es menor a $\alpha=0.05$, esto conlleva a rechazar la Ho, es decir, que si hay diferencias esenciales entre los promedios para las pruebas Saber-11, 2019 y 2020 .

Tabla 2. Prueba T-student para muestras independientes

\begin{tabular}{|c|c|c|c|c|}
\hline & & & & \\
\hline & & $\mathbf{F}$ & gl & $\begin{array}{c}\text { Sig. } \\
\text { (bilateral) }\end{array}$ \\
\hline \multirow[t]{2}{*}{ Lectura crítica } & Se asumen varianzas iguales &, 098 & 550 & 912 \\
\hline & No se asumen varianzas iguales & & 546,990 & 912 \\
\hline \multirow[t]{2}{*}{ Matemáticas } & Se asumen varianzas iguales &, 095 & 550 &, 463 \\
\hline & No se asumen varianzas iguales & & 546,430 & ,463 \\
\hline \multirow[t]{2}{*}{ Sociales } & Se asumen varianzas iguales &, 030 & 550 &, 000 \\
\hline & No se asumen varianzas iguales & & 547,484 &, 000 \\
\hline \multirow[t]{2}{*}{ Ciencias naturales } & Se asumen varianzas iguales & ,204 & 550 & ,406 \\
\hline & No se asumen varianzas iguales & & 549,482 &, 406 \\
\hline \multirow[t]{2}{*}{ Inglés } & Se asumen varianzas iguales & 3,296 & 550 &, 000 \\
\hline & No se asumen varianzas iguales & & 533,259 &, 000 \\
\hline \multirow[t]{2}{*}{ Puntaje global } & Se asumen varianzas iguales &, 021 & 550 &, 420 \\
\hline & No se asumen varianzas iguales & & 546,123 & ,421 \\
\hline
\end{tabular}

\section{METODOLOGÍA}

Se apreció en los resultados de las pruebas Saber 11 antes y dentro de la pandemia por COVID-19, que los promedios de las diferentes asignaturas evaluadas no tuvieron diferencias significativas, es decir que no se evidenció una disminución en el resultado global de las pruebas en la institución educativa General Santander del municipio de Soacha, Cundinamarca, Colombia. En 2019 el promedio global de la prueba fue de 254,04 y en la pandemia por COVID-19 fue de 256,72 .

Según los resultados ponderados, en 2020 el puntaje promedio global a nivel nacional fue sobre 500 puntos máximos, mientras que los alumnos de la institución educativa General Santander obtuvieron un puntaje global de 256,72 evidenciando un valor superior, lo cual es significativo en medio de la pandemia por COVID-19.

De acuerdo con un estudio de Díaz9, durante la pandemia por COVID-19 en la misma institución se observó que los grados de secundaria con mayor porcentaje de uso de medios de comunicación tecnológicos como correo electrónico, aplicaciones o plataformas digitales y grupo de WhatsApp, se ubicó en los grados 9,10 y 11. Esto representa una gran 
oportunidad para propiciar el interés por conocer nuevas aplicaciones y plataformas digitales que les brinden a los estudiantes alternativas de formación académica y personal, y así identificar brechas y oportunidades para progresar hacia una educación de calidad equitativa e inclusiva.

\section{CONFLICTOS DE INTERESES}

El autor declara no tener ningún tipo de conflicto de interés.

\section{REFERENCIAS}

1. Díaz Pinzón JE. (2020a). Estimación de las tasas de mortalidad y letalidad por COVID-19 en Colombia. Repert Med Cir. 2020;29(Núm. Supl.1):89-93. https://doi.org/10.31260/ RepertMedCir.01217372.1103

2. Ministerio de Educación Nacional (MEN). Estándares básicos de competencia. Pruebas Saber $11^{\circ}$ [Internet]. 2018 [citado 4 de mayo de 2021]. Disponible en: https://www.mineducacion.gov. co/portal/micrositios-preescolar-basica-y-media/Direccion-deCalidad/Referentes-de-Calidad/244735:Estandares-Basicos-deCompetencia
3. Instituto Colombiano para la Evaluación de la Educación Superior (ICFES). Guía de orientación Saber $11^{\circ}$ 2017-2 [Internet]. Icfes; 2017 [citado 4 de mayo de 2021]. Disponible en: https://bit. ly/3em07lo

4. Díaz Pinzón JE. COVID-19 en Colombia: un año después de confirmar su primer caso. Repert Med Cir. 2021;30(Núm. Supl.1):10-15. https://doi.org/10.31260/RepertMedCir.01217372.1182

5. Análisis de los resultados del contagio del COVID-19 respecto a su distribución geográfica en Colombia. Repert Med Cir. 2020;29(Núm. Supl.1):60-64. https://doi.org/10.31260/ RepertMedCir.01217372.1082

6. Díaz Pinzón JE. Estimación de la prevalencia del COVID-19 en Colombia. Repert Med Cir. 2020;29(Núm. Supl.1):99-102. https:// doi.org/10.31260/RepertMedCir.01217372.1115

7. Olea F. Técnicas estadísticas aplicadas en nutrición y salud [Internet]. 2017 [citado 2021 mayo 2]. Disponible en: https://docplayer. es/23452427-Tecnicas-estadisticas-aplicadas-en-nutricion-ysalud.html

8. IBM Corp. Publicado en. IBM SPSS Statistics para Windows, versión 25.0. Armonk; Nueva York: IBM Corp. 2017

9. Díaz Pinzón JE. Uso y apropiación escolar de tecnologías emergentes dentro del marco de educación virtual generada por el COVID-19. Repert Med Cir. 2020;29(Núm. Supl.1):113-117. Recuperado a partir de https://doi.org/10.31260/RepertMedCir.01217372.1126 